\title{
Magnesium Increases the Protective Effect of Citicoline on Aluminum Chloride-induced Cognitive Impairment
}

\author{
Ali Hosseini-Sharifabad, Mohammad Rabbani, Yasaman Seyed-Yousefi, Maryam Safavi \\ Department of Pharmacology and Toxicology and Isfahan Pharmaceutical Sciences Research Center, School of Pharmacy and Pharmaceutical \\ Sciences, Isfahan University of Medical Sciences, Isfahan, I.R. Iran
}

\begin{abstract}
Objective: Alzheimer's disease is a popular neurodegenerative disorder which is growing in the elderly people. Exposure to environmental pollutant like aluminum could trigger or accelerate its involved mechanisms like tau phosphorylation. The current study will evaluate the effect of alone or co-administration of Citicoline or/and magnesium on the aluminum chloride induced memory impairment.

Methods: Male albino mice were randomly divided into different groups $(n=7)$. Memory impairment was induced via orally administration of $300 \mathrm{mg} / \mathrm{kg}$ Aluminum Chloride for 28 days. Based on respective group, animals received 100, 250, $500 \mathrm{mg} / \mathrm{kg}$ of Citicoline or 50, 100, $150 \mathrm{mg} / \mathrm{kg}$ of Magnesium sulfate (MgSO4), intraperitoneally. In co-administration, $50 \mathrm{mg} / \mathrm{kg}$ of MgSO4 injected concomitantly with 100, 250, or $500 \mathrm{mg} / \mathrm{kg}$ of Citicoline. Rivastigmine (2 mg/kg intraperitoneally) was used as a positive control. Memory was evaluated using the Object Recognition Task (ORT) and Passive Avoidance Test (PAT).

Results: The studied doses of Citicoline or MgSO4 when administered individually showed significant increase in the discrimination index in ORT and latency time in the PAT compared to the Aluminium chloride (AICl3) treated group. Concomitant injection of $50 \mathrm{mg} / \mathrm{kg} \mathrm{MgSO} 4$ with the different doses of Citicoline strongly increased the above indices values in comparison to each alone.

Conclusion: The findings show, individual administration of Citicoline or MgSO4 inverted the AlCl3-induced memory impairment in a dose independent manner. The addition of MgSO4 to the Citicoline showed a synergistic effect in the PAT and likely additive effect in the ORT.
\end{abstract}

KEY WORDS: Citicoline; Magnesium; Aluminum chloride; Memory; Mice.

\section{INTRODUCTION}

Alzheimer's disease (AD) is a most common neurodegenerative disorder determined by memory impairment especially in elderly people [1]. It is associated with neuropathological and neurobehavioral changes in the patients. An important characteristic in AD is excessive production and accumulation of $\mathrm{A} \beta$ peptide, the pathological product of amyloid precursor protein (APP). It

Received: July 9, 2019 / Revised: September 4, 2019

Accepted: September 7, 2019

Address for correspondence: Ali Hosseini-Sharifabad Department of Pharmacology and Toxicology and Isfahan Pharmaceutical Sciences Research Center, School of Pharmacy and Pharmaceutical Sciences, Isfahan University of Medical Sciences, Hezarjarib Av, Azadi sq, Isfahan 8174673461, I.R. Iran. E-mail: hosseini_a@pharm.mui.ac.ir

ORCID: https://orcid.org/0000-0002-8483-5560 leads to large scale neuronal death, neural atrophy and the loss of synapses in the final phase of the disease $[2,3]$. Other well-known characteristic in $A D$ is the decline in cholinergic activity especially in the limbic system including hippocampus $[2,4]$. It is well established that the decrease in cholinergic markers and increase in enzyme related acetylcholine destruction occurs in $\mathrm{AD}[5,6]$. Also it is reported that the level of metals like $\mathrm{Zn}, \mathrm{Cu}, \mathrm{Fe}, \mathrm{Mn}, \mathrm{Mg}$ are negatively or positively changed in $\mathrm{AD}[7,8]$.

Although the genetic plays a key role in the incidence of $\mathrm{AD}$ [9], the environmental available agents like toxins and air pollutants could trigger or accelerate its progress. A group of environmental contaminant consists of the heavy metals. One of the most important heavy metals which assumed related to the AD is Aluminium (AI) [10]. A large number of animal experiments and clinical studies reported the important role of $\mathrm{Al}$ in the etiology and

(ㄷ) This is an Open-Access article distributed under the terms of the Creative Commons Attribution Non-Commercial License (http://creativecommons.org/licenses/by-nc/4.0) which permits unrestricted non-commercial use, distribution, and reproduction in any medium, provided the original work is properly cited. 
pathogenesis of $A D$ [11-13]. Al is one of the most abundant metal in the earth, so could infect human in different pathways [11-13]. It is documented that $\mathrm{Al}$ increases the extracellular $\mathrm{A} \beta$ generation and its aggregation. Al can alter the Calcium homeostasis, decrease the cholinergic activity and reduce the level and function of the cholinergic mediators which are the key neurochemistry processes in the learning and memory $[6,13,14]$. Also a permanent exposure to the $\mathrm{Al}$ will trigger the apoptotic process in the brain regions especially the hippocampus [15]. In other words, AI could mimic the mechanisms responsible for the pathophysiology of $A D$ and will simulate $A D$ in the lab animals.

Although several groups of drugs are implicated in the treatment of $A D$, they will show a range of side effects and could not be full successful. A recommended scenario is the use of supplements for the prevention or the treatment of $\mathrm{AD}$, alone or together with the common drugs.

Combination therapy could decrease the essential doses of each agents and consequently reduce their dose dependent adverse effects. Also in some cases the use of multiple supplements make a completely different effect compared to when they are used separately [16].

Citicoline is a phosphatidylcholine precursor that stabilizes the impaired cell membrane. Also it could supply the choline which is a vital precursor for acetylcholine production, the most important mediator in the learning and memory. Citicoline has successfully shown neuroprotective effects in the treatment of dementia following several types of brain injury e.g.: brain trauma, stroke and other vascular events [17-19]. Also, many clinical stroke trials in humans have shown that Citicoline is the only drug with neuroprotective benefits [20].

Recently, a large randomized controlled trial study found no difference in recovery effects between Citicoline and placebo groups [21]. Also it has been evidenced that the combined administration of Citicoline with an acetylcholine esterase inhibitor like Rivastigmine lead to more effectiveness in slowing the Alzheimer's progression compare to when they administered alone [22]. This emphasizes that developing combinations of agents that show synergistic benefit with Citicoline is required to enhance its effect in brain injuries.

Rare metals are other supplements could potentially show beneficial effects in AD. One of this metals which ranks as the micronutrient is Magnesium $(\mathrm{Mg})$. It has been shown that Mg prevents synaptic loss and reverse cogni- tive deficit in $\mathrm{AD}$ [23]. Mg shows neuro-protective properties and causes improving effect on memory impairments. It also could prevent the brain damage following central nervous inflammation [24,25].

Although the neuroprotective and memory enhancing effects of Citicoline or Mg have been well documented, their combined effect is still unknown. Hence, the aim of current study is to investigate whether administering Citicoline and $\mathrm{Mg}$ together has a different improving effect on Aluminium chloride ( $\mathrm{AlCl} 3$ ) induced cognitive dysfunction compared to when they administer individually.

\section{METHODS}

\section{Animals}

Adult male albino mice, weighing 25-30 g were provided from the animal house, Isfahan University of Medical Sciences. They were kept in the standard cages under normal conditions of temperature $\left(25 \pm 5^{\circ} \mathrm{C}\right)$, humidity $(60 \pm 5 \%)$, and 12/12-h light/dark cycles. Mice were given food and water ad libitum. The experimental protocol was according to the international animal right guidelines and was approved by the Animal Ethics Committee of Isfahan University of Medial Science (IR.MUI.REC.1396.3.965).

\section{Chemicals and Agents}

Citicoline was supplied from Sigma Aldrich (Taufkirchen, Germany). $\mathrm{AlCl} 3$ and Magnesium sulfate (MgSO4) were purchased from the Merck Company (Darmstadt, Germany).

\section{Experimental Design}

Animals were randomly divided to the experimental groups, 6 mice in each. They were treated according to the following schedule:

- The sham group: the mice were intact which received nothing

- The control group: animals were fed $1 \mathrm{ml}$ distilled water by gavage and were daily injected saline intraperitoneally (i.p.) for 28 consecutive days

- The AlCl3 group: animals daily received 300 mg/kg $\mathrm{AlCl} 3$ by gavage and they were i.p. injected saline for 28 consecutive days

- The Citicoline-treated groups: three groups of animals daily received $300 \mathrm{mg} / \mathrm{kg} \mathrm{AlCl} 3$ by gavage then they were i.p. injected 100, 250, or $500 \mathrm{mg} / \mathrm{kg}$ 
Citicoline for 28 days respective to their subgroup

- The magnesium-treated groups: three groups of animals daily received $300 \mathrm{mg} / \mathrm{kg} \mathrm{AlCl} 3$ by gavage then they were i.p. injected 50, 100, or $150 \mathrm{mg} / \mathrm{kg}$ MgSO4 for 28 days respective to their subgroup

- The combination-treated group: three groups of animals daily received $300 \mathrm{mg} / \mathrm{kg} \mathrm{AlCl} 3$ by gavage then they were i.p. injected $50 \mathrm{mg} / \mathrm{kg} \mathrm{MgSO} 4$ toghether with 100, 250, or $500 \mathrm{mg} / \mathrm{kg}$ Citicoline (on the other side) for 28 days respective to their subgroup

- The rivastigmine group: animals daily received 300 $\mathrm{mg} / \mathrm{kg} \mathrm{AICl} 3$ by gavage and they were i.p. injected 2 $\mathrm{mg} / \mathrm{kg}$ rivastigmine for 28 consecutive days

\section{Behavioral Studies}

\section{Object Recognition Task (ORT)}

The ORT procedure which previously was explained in details [26] was employed to evaluate the animal memory. In brief, its apparatus included a circular arena, two different sets of objects including a massive aluminum cube and a massive aluminum cube with a tapering top. Each object was available in triplicate. The objects could not be displaced by mouse.

24 hours after the end of treatments the animals underwent the object recognition task. ORT consisted of three defined phases: a training session or first trial $\left(T_{1}\right)$, a training-test interval, and a test session or second trial $\left(\mathrm{T}_{2}\right)$ lasting 5, 60 and 5 minutes respectively. During the $T_{1}$ animals encountered two identical objects $\left(A_{1}\right.$ and $\left.A_{2}\right)$ which were placed in a symmetrical position about $10 \mathrm{~cm}$ away from the wall. In the $T_{2}$ trial they faced one identical and one novel object ( $\mathrm{A}$ and $\mathrm{B}$ ) to explore. Exploration was defined as: directing the nose to the object at a distance of no more than $2 \mathrm{~cm}$ and/or touching the object with the nose. Sitting on the object was not considered exploratory behavior. The exploration time (seconds) for each object in each trial was recorded and the following memory indicating factors were calculated.

$\mathrm{e}_{1}$ : The total exploration time of both objects in the first trial $\left(\mathrm{eA}_{1}+\mathrm{eA}_{2}\right)$

$\mathrm{e}_{2}$ : The total exploration time of both objects in the second trial $(\mathrm{eA}+\mathrm{eB})$

$\mathrm{d}_{2}$ : discrimination index $(\mathrm{eB}-\mathrm{eA}) /(\mathrm{eB}+\mathrm{eA})$

$\mathrm{d}_{2}$ is an index indicates the discrimination between the new and the familiar objects. Its value varies between +1 and -1 , where a positive score indicates more time spent with the novel object, a negative score indicates more time spent with the familiar object, and a zero score indicates a null preference. In every section, animals who explored less than 10 seconds in the second trial $\left(\mathrm{e}_{2}<10\right)$ were deleted from the analysis.

\section{Passive Avoidance Test (PAT)}

PAT was used to evaluate the animals' conditional memory [27]. Its apparatus consisted of two identical chamber with a metallic floor, light and dark chambers. There was a door between the chambers. The PAT procedure was performed by three different phases: a habituation, a training and a test phase. In habituation session, the mouse was put inside the light chamber. After $6 \mathrm{sec}$ onds the door was opened and the mouse was allowed to move freely to the dark chamber for 2 minutes. Immediately after the mouse entered the dark area, the door was closed and it was returned to the home cage. 30 minutes after the habituation phase, the training session took place. In that, the mouse was placed in the light chamber and allowed for 3 minutes to enter the dark ones. As soon as, the mouse arrived in dark part, the door was closed and an electric shock (1 mA for 3 seconds) was applied. 2 minutes later, the mouse was again placed in the light area. Failure to enter the dark area in 120 seconds was considered as successful learning. If the animal entered the dark area, the shock was applied again. This process was repeated until the mouse learned not to enter the dark chamber. 24 hours after the train phase, the test trial was done. In this trial the time lasted the animal entered the dark area called latency time was recorded and implicated as a memory indicating factor.

\section{Statistical Analysis}

The data of different memory evaluating factors presented as mean \pm standard error of the mean. The values were analyzed using one way analysis of variance (ANOVA). For statistical analysis the Graphpad Prism V.5 software was used. For multiple comparisons we used the Tukey post-hoc tests. $p<0.05$ were considered statistically significant. 


\section{RESULTS}

\section{Effect of Different Doses of Citicoline on the $d_{2}$ Factor in ORT}

Administration of $\mathrm{AlCl} 3$ at the dose of $300 \mathrm{mg} / \mathrm{kg}$ significantly decreased the $d_{2}$ index to the negative value compared to the control group. All of the experimented doses of Citicoline, 100, 250, or $500 \mathrm{mg} / \mathrm{kg}$, remarkably inverted the $\mathrm{d}_{2}$ value compared to the AlCl3-treated animals and increased it to the normal level. There was no statistical difference between the applied doses of Citicoline. The injection of $2 \mathrm{mg} / \mathrm{kg}$ Rivastigmine significantly increased the $d_{2}$ index up to normal level in comparison with the $\mathrm{AlCl} 3$ treated group (Fig. 1).

\section{Effect of Different Doses of $\mathrm{MgSO}_{4}$ on the $d_{2}$ Factor in ORT}

As shown in Figure 2 the injection of 50, 100, or 150 $\mathrm{mg} / \mathrm{kg}$ MgSO4 significantly increased the $d_{2}$ index in $\mathrm{AlCl} 3$ treated animals up to the control level. There was no statistical differences between the studied doses of $\mathrm{MgSO} 4$ in the $\mathrm{d}_{2}$ index. Rivastigmine at the dose of 2 $\mathrm{mg} / \mathrm{kg}$ encountered the decreasing effect of $\mathrm{AlCl} 3$ in $\mathrm{d}_{2}$

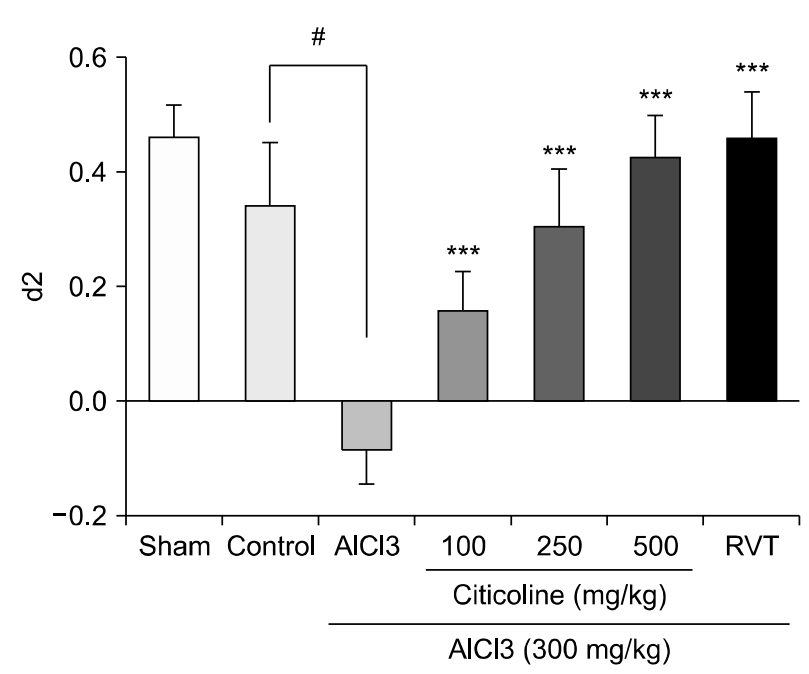

Fig. 1. Effects of different doses of Citicoline $(100,250,500 \mathrm{mg} / \mathrm{kg})$ on $\mathrm{d}_{2}$ index in Object Recognition task. The $\mathrm{d}_{2}$ index values have been shown for the studied group. The data represent as means \pm standard error of mean of 7 mice per group. $\mathrm{AlCl} 3$ was orally administrated for 28 days. Citicoline was injected intraperitoneally for 28 consecutive days.

$\mathrm{RVT}$, rivastigmine injected intraperitoneally for 28 days at the dose of $2 \mathrm{mg} / \mathrm{kg}$; $\mathrm{AlCl} 3$, Aluminium chloride.

${ }^{* * *} p<0.001$ vs. $\mathrm{AlCl} 3$-treated group. ${ }^{\#} p<0.001$ vs. control vehicle treated group (Tukey test). index.

\section{Effect of Co-treatment of Citicoline and $\mathrm{MgSO} 4$ in Mice on the $d_{2}$ Factor in ORT}

Co-administration of 100,250 , or $500 \mathrm{mg} / \mathrm{kg}$ of Citicoline with $50 \mathrm{mg} / \mathrm{kg} \mathrm{MgSO} 4$ significantly increased the $d_{2}$ factor compared to the respective Citicoline individual treated group $(p<0.001, p<0.05, p<0.001$ respectively). Co-administartion of $50 \mathrm{mg} / \mathrm{kg} \mathrm{MgSO} 4$ with 100,250 , or $500 \mathrm{mg} / \mathrm{kg}$ of Citicoline remarkably increased the $\mathrm{d}_{2}$ factor compared to when $50 \mathrm{mg} / \mathrm{kg} \mathrm{MgSO} 4$ injected alone $(p<0.001)$. There is no statistically differences between the doses of Citicoline in co-treatment with MgSO4 (Fig. 3).

\section{Effects of Different Doses of Citicoline on the Latency Time in Passive Avoidance Test}

Oral consumption of $\mathrm{AlCl} 3$ decreased the latency time showed by mouse in passive avoidance $(p<0.001) .500$ $\mathrm{mg} / \mathrm{kg}$ Citicoline significantly increased the latency time in comparison to the $\mathrm{AlCl} 3$-treated animals $(p<0.001)$. 100 or $250 \mathrm{mg} / \mathrm{kg}$ Citicoline did not show a difference in the latency time compared to the $\mathrm{AlCl} 3$ treated group.

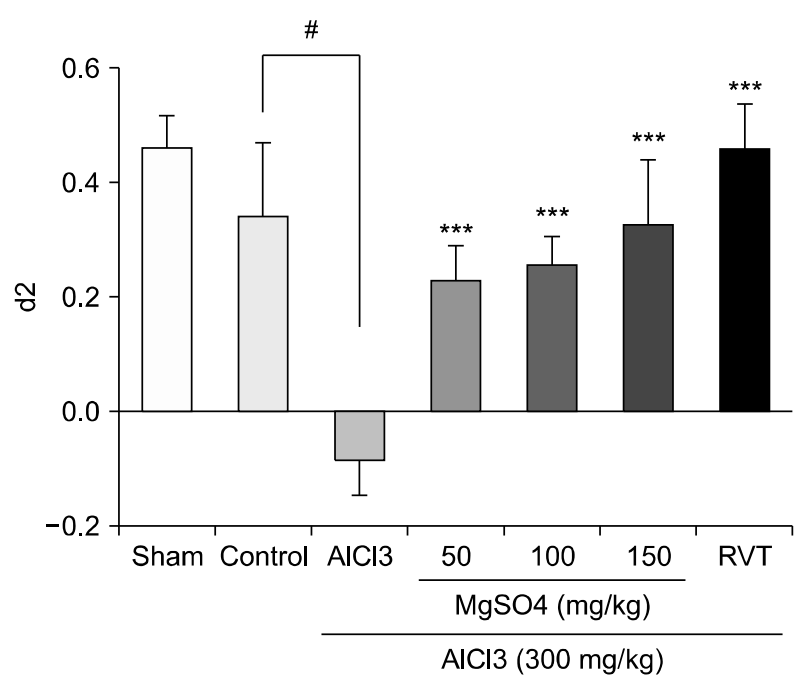

Fig. 2. Effects of different doses of MgSO4 (50, 100, $150 \mathrm{mg} / \mathrm{kg}$ ) on $\mathrm{d}_{2}$ index in Object Recognition task. The $\mathrm{d}_{2}$ index values have been shown for the studied groups. The data represent as means \pm standard error of mean of 7 mice per group. $\mathrm{AlCl} 3$ was orally administrated for 28 days. MgSO 4 was injected intraperitoneally for 28 consecutive days.

RVT, rivastigmine injected intraperitoneally for 28 days at the dose of $2 \mathrm{mg} / \mathrm{kg}$; AlCl3, Aluminium chloride; MgSO4, Magnesium sulfate.

${ }^{* * *} p<0.001$ vs. $\mathrm{AlCl} 3$-treated group. ${ }^{\#} p<0.001$ vs. control vehicle treated group (Tukey test). 


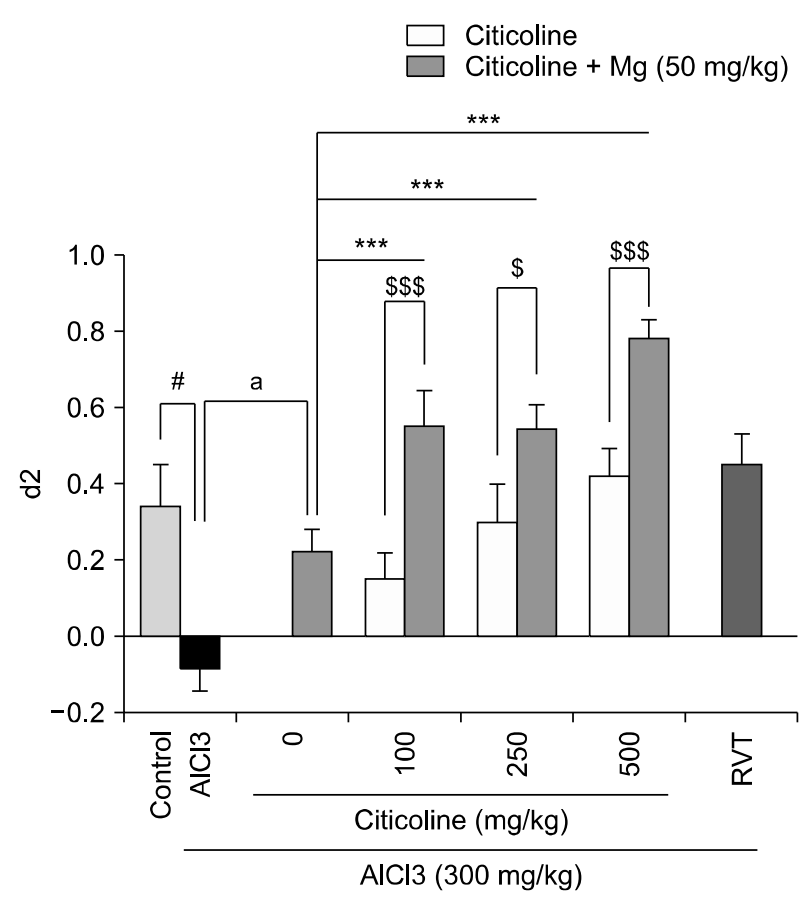

Fig. 3. Effects of co-administration of Citicoline (100, 250, 500 $\mathrm{mg} / \mathrm{kg}$ ) and $\mathrm{MgSO} 4(50 \mathrm{mg} / \mathrm{kg})$ on $\mathrm{d}_{2}$ index in Object Recognition task. The $d_{2}$ index values have been shown for the studied group. The data represent as means \pm standard error of mean of 7 mice per group. $\mathrm{AlCl} 3$ was orally administrated for 28 days. Citicoline and $\mathrm{MgSO} 4$ were injected intraperitoneally for 28 consecutive days.

$\mathrm{RVT}$, rivastigmine injected intraperitoneally for 28 days at the dose of $2 \mathrm{mg} / \mathrm{kg}$; $\mathrm{AlCl} 3$, Aluminium chloride; MgSO4, Magnesium sulfate. ${ }^{a} p<0.001$ vs. $\mathrm{AlCl} 3$-treated group. ${ }^{* * *} p<0.001$ vs. MgSO4-treated group. ${ }^{\#} p<0.001$ vs. control vehicle treated group. ${ }^{\$} p<0.05,{ }^{\$ \$ \$} p$ $<0.001$ vs. respective Citicoline treated group (Tukey test).

Rivastigmine completely inverted the AICl3-decreased latency time almost to the normal level (Fig. 4).

\section{Effects of Different Doses of MgSO4 on the Latency Time in Passive Avoidance Test}

Injection of 50, 100, or $150 \mathrm{mg} / \mathrm{kg} \mathrm{MgSO} 4$ statistically increased the latency time in passive avoidance test in comparison to the $\mathrm{AlCl} 3$ treated group $(p<0.05)$. There is no differences between the different studied doses of $\mathrm{MgSO} 4$ in latency time (Fig. 5).

\section{Effects of Co-administration of Citicoline and $\mathrm{MgSO} 4$ on Latency Time in Passive Avoidance Test}

As shown in Figure 6, co-administration of $\mathrm{MgSO} 4$ with 100,250 , or $500 \mathrm{mg} / \mathrm{kg}$ Citicoline remarkably increased the latency time compared to the groups which received respective dose of Citicoline, individually $(p<0.001)$. However the co-treatment of Citicoline and $\mathrm{MgSO} 4$ sig-

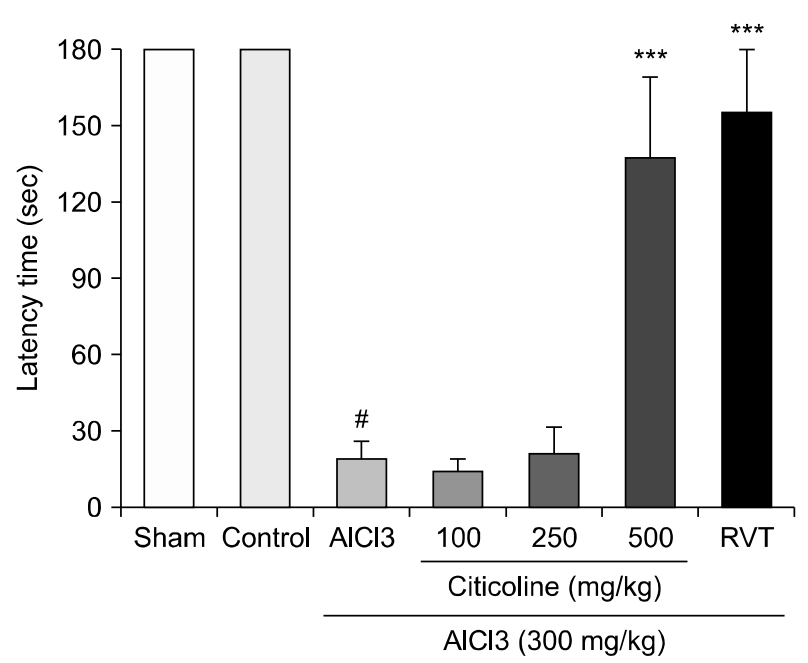

Fig. 4. Effects of different doses of Citicoline $(100,250,500 \mathrm{mg} / \mathrm{kg}$ ) on the latency time in Passive Avoidance test. The latency index values have been shown for the studied group. The data represent as means \pm standard error of mean of 7 mice per group. $\mathrm{AlCl} 3$ was orally administrated for 28 days. Citicoline was injected intraperitoneally for 28 consecutive days.

$\mathrm{RVT}$, rivastigmine injected intraperitoneally for 28 days at the dose of $2 \mathrm{mg} / \mathrm{kg}$; $\mathrm{AlCl} 3$, Aluminium chloride.

${ }_{* * *} p<0.001$ vs. $\mathrm{AlCl} 3$-treated group. ${ }^{*} p<0.001$ vs. control vehicle treated group (Tukey test).

nificantly increased the latency time in comparison to alone MgSO 4 administration $(p<0.001)$.

\section{DISCUSSION}

The present study evaluated the effect of Citicoline and Magnesium when administered alone or in combination on the memory of mice. It was observed, the ingestion of $\mathrm{AlCl} 3$ led to memory impairment in mice both in ORT and in passive avoidance test. This is consistent with the previous studies which demonstrated Aluminum is accumulated in the hippocampus and cortex-the most important sites of memory and learning $[3,28]$. A specific high affinity receptor for transferrin available in the BBB is responsible for the Aluminum entrance into the brain [29]. These studies showed memory deterioration will occur following the chronic intake of $\mathrm{AlCl} 3$ [6]. It is considered that a wide range of mechanisms are involved in the $\mathrm{Al}$-induced memory impairment. The overexpression of APP, A $\beta$, nuclear factor- $\mathrm{\kappa B}$, the increased $\mathrm{AChE}$ activity, the increase in nitric oxide release, oxidative stress and lipid peroxidation and consequently neuronal apoptosis are the common reported mechanisms for $\mathrm{AlCl} 3$ cognitive 


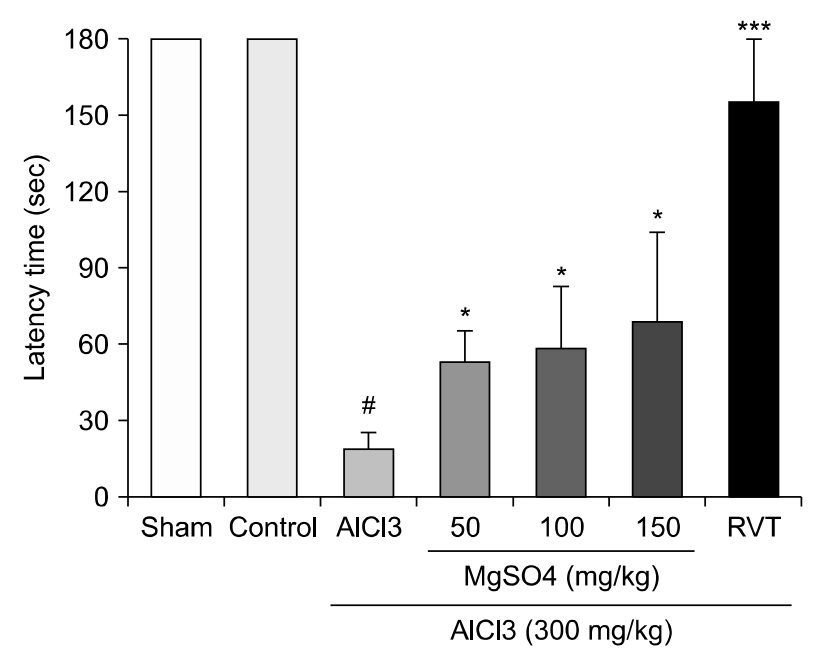

Fig. 5. Effects of three different doses of MgSO4 (50, 100, 150 $\mathrm{mg} / \mathrm{kg}$ ) on latency index in Passive Avoidance test. The latency index values have been shown for the studied group. The data represent as means \pm standard error of mean of 7 mice per group. $\mathrm{AlCl} 3$ was orally administrated for 28 days. MgSO4 was injected intraperitoneally for 28 consecutive days.

$\mathrm{RVT}$, rivastigmine injected intraperitoneally for 28 days at the dose of $2 \mathrm{mg} / \mathrm{kg}$; AlCl3, Aluminium chloride; MgSO4, Magnesium sulfate. ${ }^{*} p<0.05,{ }^{* * *} p<0.001$ vs. AlCl3-treated group. ${ }^{*} p<0.001$ vs. control vehicle treated group (Tukey test).

toxicity. In addition displacement of calcium hemostasis as a vital ion in neural processes is other important mechanism for $\mathrm{AlCl} 3$ memory deterioration $[4,6,13,14,30]$. Rivastigmine function as a well-known anti-Alzheimer drug in the current memory evaluating methods states the ORT and PA tests are reliable methods for the measurement of memory in this study [31].

Our results showed, the administration of Citicoline in different doses improved the $\mathrm{AlCl} 3$-induced memory impairment to the normal level in ORT. This improving effect was statistically equal for all the studied doses of Citicoline. In other words there was no dose dependency in this manifestation for Citicoline. In the passive avoidance test a significant improving effect was observed only at the high dose $(500 \mathrm{mg} / \mathrm{kg}$ ) of Citicoline. The observed effects related to Citicoline are consistent with the previous studies reported the beneficial effects of Citicoline in behavioral activity. For example, Abdel-Zaher et al. [17], showed Citicoline protects the neurons against the aluminum induced destructions and improves its consequent memory impairment. Different mechanisms concern to the memory toxicity of Aluminum lead to the destruction of cytoplasmic membrane of neurons and impairment of their integrity $[13,14]$. Citicoline as a pre-

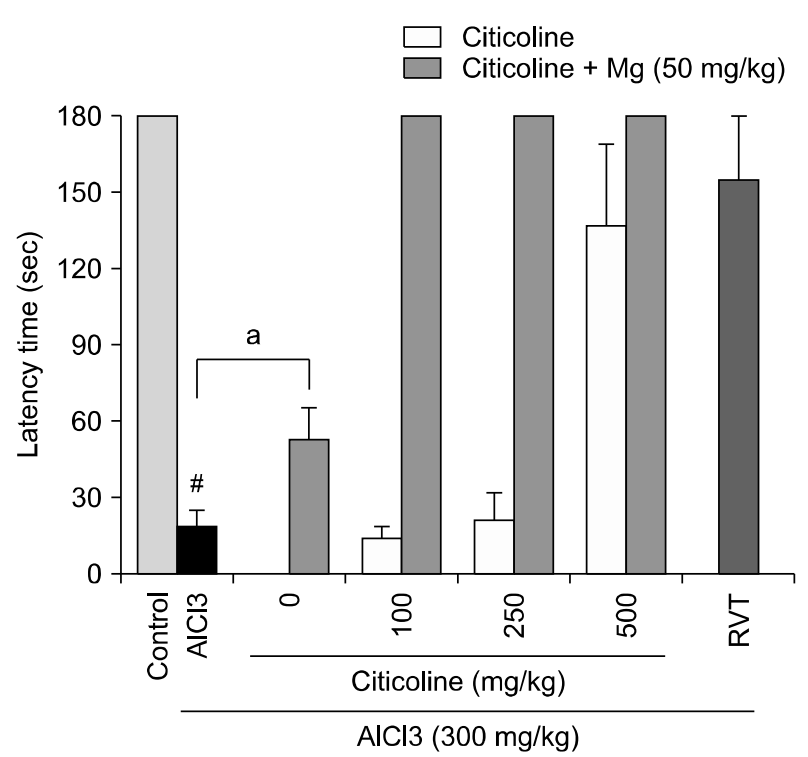

Fig. 6. Effects of co-administration of Citicoline (100, 250, 500 $\mathrm{mg} / \mathrm{kg}$ ) and MgSO4 (50 mg/kg) on latency time in Passive Avoidance test. The latency index values have been shown for the studied group. The data represent as means \pm standard error of mean of 7 mice per group. $\mathrm{AlCl} 3$ was orally administrated for 28 days. Citicoline and MgSO4 were injected intraperitoneally for 28 consecutive days.

RVT, rivastigmine injected intraperitoneally for 28 days at the dose of $2 \mathrm{mg} / \mathrm{kg}$; $\mathrm{AlCl} 3$, Aluminium chloride; MgSO4, Magnesium sulfate.

${ }^{a} p<0.05$ vs. $\mathrm{AlCl} 3$-treated group. ${ }^{\#} p<0.001$ vs. control vehicle treated group (Tukey test).

cursor of choline is implicated to synthesis phosphatidylcholines as well as acetylcholine. Phosphatidylcholines are a class of phospholipids which are a major component of biological membrane [32,33]. Citicoline improves the AlCl3-induced memory impairment likely via the repair of cytoplasmic membrane by increase the formation of Phosphatidylcholine. In addition it can increase the level of acetylcholine and recompense the Aluminum induced acetylcholine esterase hyperactivity [22]. Citicoline could prevent the Aluminum-induced glutamate and $\mathrm{NO}$ formation and consequently encounter the neuronal oxidative stress and apoptosis $[17,19]$.

We showed, MgSO4 in all studied doses significantly reversed the $\mathrm{AlCl} 3$-diminushed memory to the normal level. Although this useful effect occurred both in the ORT and the passive avoidance test, it was more prominent in the ORT method. The improving effect began following administration of $50 \mathrm{mg} / \mathrm{kg} \mathrm{MgSO} 4$ and there was no significant difference compared to higher administered doses. The current obtained effects of $\mathrm{MgSO} 4$ on the memory are consistent with several studies which express improving effect of magnesium on the memory impairments. Nootarki 
et al. showed, magnesium plays a neuro-protective role and improve the atropine induced memory deterioration in mice [24]. Lamhot et al. [25] reported that magnesium therapy prevents white and gray matter damages caused by mother's inflammatory lesions. Also because of the depleted level of magnesium in Alzheimer disease, its administration is highly recommended. It has been proven that elevation of magnesium prevents synaptic loss and reverses cognitive deficits in mouse model of $A D$ [23]. It seems that displacement of Aluminum by magnesium is an important reason responsible for its protective effects in aluminum induced destructions. Magnesium alternatively could play the role of calcium in some biological process including learning and memory. In addition it has been reported that magnesium could show cholinomimetic effects and improve the cholinergic pathways activities [34]. There are evidences which illustrated Magnesium stabilizes the blood brain barrier and increases its integrity [35]. The last mechanism could limit the aluminum access to the central nervous system.

An interesting outcome of present study was that the improving effect on Al-induced memory impairment significantly increased after combined Citicoline and $\mathrm{MgSO} 4$ treatment in both ORT and PA methods. In the ORT, the memory improving effect of Citicoline plus MgSO4 was statistically better than alone Citicoline or MgSO4 administration, while we actually found their combination synergistically elevated the conditional memory in the PA. It can be assumed that the combination therapy of Citicoline and MgSO4 will trigger more effective pathways or augment different mechanisms in the Al-treated mice. It also could be supposed that Citicoline facilitates the Magnesium involving mechanisms in concomitant administration. Also the improvement of Citicoline incorporation in cytoplasmic membrane by Magnesium could be responsible for the more increasing effects in combination treatment. More studies are needed to determine the underlying molecular mechanisms of memory enhancement effects following co-administration of Citicoline and MgSO4.

The findings show Citicoline prevented the memory impairment caused by $\mathrm{AlCl} 3$. MgSO4 also inverted the destructive effects of $\mathrm{AlCl} 3$ on the memory. Interestingly, the concomitant administration of Citicoline and MgSO4 led to synergistic effect in the PAT and likely additive effect in the ORT in comparison to when they administered alone.

\section{- Acknowledgments}

We would like to acknowledge the School of Pharmacy research department in Isfahan University of Medical Sciences, Isfahan, I.R. Iran for their co-operation and financial supports (Grant No. 396965). We thank Mrs. Moradi and Mr. Sharifi for their help in the pharmacology lab. We have no conflicts of interest to disclose.

\section{- Conflicts of Interest}

No potential conflict of interest relevant to this article was reported.

\section{Author Contributions}

Conceptualization and supervision: Ali HosseiniSharifabad. Supervision: Mohammad Rabbani. Data acquisition: Yasaman Seyed-Yousefi. Co-worker: Maryam Safavi.

\section{ORCID}

Ali Hosseini-Sharifabad

https://orcid.org/0000-0002-8483-5560

Mohammad Rabbani

https://orcid.org/0000-0002-5457-7185

Yasaman Seyed-Yousefi

https://orcid.org/0000-0002-3765-7001

Maryam Safavi https://orcid.org/0000-0002-1356-0424

\section{REFERENCES}

1. Ishrat $\mathrm{T}$, Parveen $\mathrm{K}$, Khan MM, Khuwaja G, Khan MB, Yousuf $\mathrm{S}$, et al. Selenium prevents cognitive decline and oxidative damage in rat model of streptozotocin-induced experimental dementia of Alzheimer's type. Brain Res 2009;1281:117-127.

2. Area-Gomez E, Schon EA. On the pathogenesis of Alzheimer's disease: the MAM hypothesis. FASEB J 2017;31:864-867.

3. Kocahan S, Doğan Z. Mechanisms of Alzheimer's disease pathogenesis and prevention: the brain, neural pathology, $\mathrm{N}$-methyl-D-aspartate receptors, tau protein and other risk factors. Clin Psychopharmacol Neurosci 2017;15:1-8.

4. Huang Y, Huang X, Zhang L, Han F, Pang KL, Li X, et al. Magnesium boosts the memory restorative effect of environmental enrichment in Alzheimer's disease mice. CNS Neurosci Ther 2018;24:70-79.

5. Hampel H, Mesulam MM, Cuello AC, Farlow MR, Giacobini $\mathrm{E}, \mathrm{Grossberg} \mathrm{GT}$, et al. The cholinergic system in the pathophysiology and treatment of Alzheimer's disease. Brain 2018;141:1917-1933. 
6. Jankowska A, Madziar B, Tomaszewicz M, Szutowicz A. Acute and chronic effects of aluminum on acetyl-CoA and acety/choline metabolism in differentiated and nondifferentiated SN56 cholinergic cells. J Neurosci Res 2000;62:615-622.

7. Famitafreshi $\mathrm{H}$, Karimian M. Deficit in memory is associated with paradoxical regulation of magnesium and manganese in isolated male rats. Ann Neurosci 2018;25:241-246.

8. Kawahara M, Kato-Negishi M. Link between aluminum and the pathogenesis of Alzheimer's disease: the integration of the aluminum and amyloid cascade hypotheses. Int J Alzheimers Dis 2011;2011:276393.

9. Shao W, Peng D, Wang X. Genetics of Alzheimer's disease: from pathogenesis to clinical usage. J Clin Neurosci 2017;45: 1-8.

10. Barceló J, Poschenrieder C. Fast root growth responses, root exudates, and internal detoxification as clues to the mechanisms of aluminium toxicity and resistance: a review. Environ Exp Bot 2002;48:75-92.

11. Klotz K, Weistenhöfer W, Neff F, Hartwig A, van Thriel C, Drexler $\mathrm{H}$. The health effects of aluminum exposure. Dtsch Arzteb/ Int 2017;114:653-659.

12. McLachlan DRC, Bergeron C, Alexandrov PN, Walsh WJ, Pogue Al, Percy ME, et al. Aluminum in neurological and neurodegenerative disease. Mol Neurobiol 2019;56:1531-1538.

13. Shaw CA, Tomljenovic L. Aluminum in the central nervous system (CNS): toxicity in humans and animals, vaccine adjuvants, and autoimmunity. Immunol Res 2013;56:304-316.

14. Platt B, Fiddler G, Riedel G, Henderson Z. Aluminium toxicity in the rat brain: histochemical and immunocytochemical evidence. Brain Res Bull 2001;55:257-267.

15. Zhang QL, Jia L, Jiao X, Guo WL, Ji JW, Yang HL, et al. APP/PS1 transgenic mice treated with aluminum: an update of Alzheimer's disease model. Int J Immunopathol Pharmacol 2012;25:49-58.

16. Atri A. Current and future treatments in Alzheimer's disease. Semin Neurol 2019;39:227-240.

17. Abdel-Zaher AO, Hamdy MM, Abdel-Rahman MS, Abd El-Hamid DH. Protective effect of citicoline against aluminum-induced cognitive impairments in rats. Toxicol Ind Health 2017;33:308-317.

18. Andersen M, Overgaard K, Meden P, Boysen G, Choi SC. Effects of citicoline combined with thrombolytic therapy in a rat embolic stroke model. Stroke 1999;30:1464-1471.

19. Lee HJ, Kang JS, Kim YI. Citicoline protects against cognitive impairment in a rat model of chronic cerebral hypoperfusion. J Clin Neurol 2009;5:33-38.

20. Alvarez-Sabín J, Román GC. The role of citicoline in neuroprotection and neurorepair in ischemic stroke. Brain Sci 2013;3:1395-1414.

21. Secades JJ, Alvarez-Sabín J, Castillo J, Díez-Tejedor E,
Martínez-Vila E, Ríos J, et al. Citicoline for acute ischemic stroke: a systematic review and formal meta-analysis of randomized, double-blind, and placebo-controlled trials. J Stroke Cerebrovasc Dis 2016;25:1984-1996.

22. Castagna A, Cotroneo AM, Ruotolo G, Gareri P. The CITIRIVAD study: CITIcoline plus RIVAstigmine in elderly patients affected with dementia study. Clin Drug Investig 2016;36: 1059-1065.

23. Slutsky I, Abumaria N, Wu LJ, Huang C, Zhang L, Li B, et al. Enhancement of learning and memory by elevating brain magnesium. Neuron 2010;65:165-177.

24. Nootarki ZS, Kesmati M, Borujeni MP. Effect of magnesium oxide nanoparticles on atropine-induced memory impairment in adult male mice. Avicenna J Neuro Psych Physio 2015;2:e36924.

25. Lamhot VB, Khatib N, Ginsberg Y, Anunu R, Richter-Levin G, Weiner $Z$, et al. Magnesium sulfate prevents maternal inflammation-induced impairment of learning ability and memory in rat offspring. Am J Obstet Gynecol 2015;213:851.e1851.e8.

26. Leger M, Quiedeville A, Bouet V, Haelewyn B, Boulouard M, Schumann-Bard $\mathrm{P}$, et al. Object recognition test in mice. Nat Protoc 2013;8:2531-2537.

27. Kameyama T, Nabeshima T, Kozawa T. Step-down-type passive avoidance- and escape-learning method. Suitability for experimental amnesia models. J Pharmacol Methods 1986; 16:39-52.

28. Zhang L, Jin C, Lu X, Yang J, Wu S, Liu Q, et al. Aluminium chloride impairs long-term memory and downregulates CAMP-PKA-CREB signalling in rats. Toxicology 2014;323: 95-108.

29. Wang L. Entry and deposit of aluminum in the brain. Adv Exp Med Biol 2018;1091:39-51.

30. Walton JR, Wang MX. APP expression, distribution and accumulation are altered by aluminum in a rodent model for Alzheimer's disease. J Inorg Biochem 2009;103:1548-1554.

31. Birks JS, Grimley Evans J. Rivastigmine for Alzheimer's disease. Cochrane Database Syst Rev 2015;(4):CD001191.

32. Iulia C, Ruxandra T, Costin LB, Liliana-Mary V. Citicoline - a neuroprotector with proven effects on glaucomatous disease. Rom J Ophthalmol 2017;61:152-158.

33. Tayebati SK, Amenta F. Choline-containing phospholipids: relevance to brain functional pathways. Clin Chem Lab Med 2013;51:513-521.

34. Hutter OF, Kostial K. Effect of magnesium ions upon the release of acetylcholine. J Physiol 1953;120:53P.

35. Shadman J, Sadeghian N, Moradi A, Bohlooli S, Panahpour H. Magnesium sulfate protects blood-brain barrier integrity and reduces brain edema after acute ischemic stroke in rats. Metab Brain Dis 2019;34:1221-1229. 